OSA group compared with not OSA along with higher AHI and ODI. The BMI were similar between the two groups and there was no difference in the ESS. We then compared the symptoms of initiation and maintenance insomnia between the two groups. $75 \%$ of patients with confirmed diagnosis of OSA experienced insomnia symptoms. We found that there was no difference in symptoms of time to get to sleep, difficulty to get to sleep and difficulty to remain asleep between those with OSA and those with no evidence of OSA. (see table 1).

Conclusion This suggests there is a large proportion of patients presenting to our service with difficulty falling or staying asleep. There are a similar proportion of patients describing these initiation and maintenance insomnia symptoms in those diagnosed with OSA compared to those where OSA was excluded.

\section{P63 ASSESSING WHICH PATIENT RELEVANT FEATURES OF AN OSCILLATING POSITIVE EXPIRATORY PRESSURE (OPEP) DEVICE ARE MOST IMPORTANT IN THE REAL WORLD - RESULTS FROM AN INDEPENDENT CLINICAL ASSESSMENT IN UK}

A Bracey, I Suggett. Trudell Medical International, Hampshire, UK

10.1136/thorax-2021-BTSabstracts. 173

Introduction and Objectives OPEP devices can be used to manage a number of different respiratory conditions by providing airway clearance therapy to mobilize and clear excess mucous from the lungs. This assessment investigated the relative importance of a number of different patient relevant features when selecting an OPEP device.

Methods The survey was completed, as part of an independent clinical assessment of an OPEP device (Aerobika*, Trudell Medical International), across 23 UK centres by respiratory physiotherapists. They were asked to note, for each patient, the respiratory condition being managed and to select which device features would be important when selecting an OPEP device for that patient. Up to fourteen different features could be selected and these covered topics related to a) ease of use/ cleaning, b) clinical adaptability/evidence and c) device robustness/quality.

Results Data related to 156 individual patients was collected, covering CF, bronchiectasis and COPD conditions. The most important features noted were generally related to device ease of use and associated attributes. These were highest overall and for each specific respiratory condition. Orientation independence and the ability to easily take apart and clean were identified specifically as high rating factors. When the data was analysed by respiratory condition and the top 5 features compared, there was generally agreement across different conditions, although interestingly the attribute 'clinically proven' was of a greater relative importance when selecting for COPD and bronchiectasis patients than for CF and the ability to use at low expiratory flows was higher rated for COPD than the other two conditions.

Conclusions In conclusion, the results reflect the pragmatic and clinically relevant perspective of selecting a device that a patient can easily use and therefore is more likely to use in the real world.

Please refer to page A192 for declarations of interest related to this abstract.

\section{P64 PREVALENCE OF BREATHING PATTERN DISORDERS WITH CHRONIC REFRACTORY COUGH AND THE OUTCOMES OF PHYSIOTHERAPY MANAGEMENT}

${ }^{1} \mathrm{R}$ De Vos, ${ }^{2} \mathrm{H}$ Rupani, ${ }^{1} \mathrm{~T}$ Brown, 'L Fox, 'L Wiffen, ${ }^{1} \mathrm{AJ}$ Chauhan. ${ }^{1}$ Portsmouth Hospitals University NHS Trust, Portsmouth, UK; ${ }^{2}$ University Hospital Southampton NHS Trust, Southampton, UK

\subsection{6/thorax-2021-BTSabstracts. 174}

Background Chronic refractory cough (CRC) is described as a cough that persists despite guideline-based treatment. Once medical management is optimised the mainstay of treatment is to reduce upper airway hypersensitivity. The prevalence of breathing pattern disorders (BPD) with CRC is increasingly recognised and treatment by specialist respiratory physiotherapists (SRP) aims to reduce symptom burden.

Objectives

- To determine the prevalence of comorbid BPD with CRC.

- To assess improvement in cough following SRP input.

Methods We reviewed 34 patients (79.4\% female) with CRC referred to a SRP over a 6 month period. Patients were assessed for BPD and treatment included breathing pattern retraining alongside cough management and suppression techniques. Cough severity and impact of cough on quality of life (QOL) was scored on a 10-point visual analogue scale (VAS) pre and post treatment.

Results

- Average length of CRC was 7.8 years (range 1-25 years)

- Patients were reviewed by the same SRP an average of 3 times (range 2-5)

- $33 / 34$ (97\%) had a comorbid BPD as assessed by the SRP

- 31/34 completed treatment with 28/31 (90\%) reporting improvement in symptoms

\section{Abstract P64 Table 1}

\begin{tabular}{llll}
\hline & $\begin{array}{l}\text { Pre SRP } \\
\text { intervention }\end{array}$ & $\begin{array}{l}\text { Post SRP } \\
\text { intervention }\end{array}$ & P value \\
\hline $\begin{array}{l}\text { VAS score for Cough severity } \\
\text { (median, range) }\end{array}$ & $6,3-10$ & $2,0-10$ & $<0.0001$ \\
$\begin{array}{l}\text { VAS score for QOL related to cough } \\
\text { (median, range) }\end{array}$ & $6,0-10$ & $2,0-7$ & $<0.0001$ \\
\hline
\end{tabular}

Conclusion BPD commonly coexists with CRC.

SRP intervention in patients with CRC improves symptoms and quality of life related to cough.

SRP should therefore be an integral part of a CRC clinic, with routine assessment for BPD carried out.

\section{P65 REMOTE DELIVERY OPTIONS FOR SELF-MANAGEMENT PROGRAMMES FOR PATIENTS WITH COPD DURING THE COVID-19 PANDEMIC. UPTAKE, COMPLETION AND CLINICAL OUTCOMES}

1,2L Houchen-Wolloff, ${ }^{1} \mathrm{~S}$ Ward, ${ }^{1} \mathrm{EJ}$ Chaplin, ${ }^{1} \mathrm{NY}$ Gardiner, ${ }^{1,2} \mathrm{SJ}$ Singh. ${ }^{1}$ University Hospitals of Leicester, Leicester, UK; ${ }^{2}$ University of Leicester, Leicester, UK

\subsection{6/thorax-2021-BTSabstracts. 175}

Introduction Face-to-face pulmonary rehabilitation (PR) programmes were largely stopped in the UK in March 2020 due 